\title{
EFFICACY OF USING SIMILE COMPLETION TASKS AS A MEASURE TO EVALUATE THE FIGURATIVE LANGUAGE ABILITIES IN ADOLOSCENTS AGED BETWEEN 10-15 YEARS
}

\author{
Karuppali $S,{ }^{1^{*}}$ Bhat $\mathrm{JS}^{1}$ \\ ${ }^{1}$ Department of Audiology and Speech Language Pathology, \\ Kasturba Medical College, Manipal University, Mangalore, Karnataka
}

*Corresponding Author: Sudhin Karuppali

Assistant Professor-Senior Scale, Department of Audiology and Speech Language Pathology, Kasturba Medical College (Manipal University), Mangalore - 575001

Email:sudhin.karuppali@manipal.edu

\begin{abstract}
Background: Language development is an ongoing process. The understanding of figurative expressions such as similes begins during the preschool years with subsequent improvement throughout childhood, adolescence, and into adulthood. Studies pertaining to the development of such higher language skills are limited, especially in a multilingual setup like India.

Methods: Participants were divided into six groups (10-10,11 to 15-15.11 years), with each group consisting of 5 children each. The groups selected for the present study were also classified into the Piaget's cognitive stages. The participants were required to fill in the incomplete figurative expressions (similes). The responses were recorded. Univariate Analysis of Variance was employed to determine the main significant difference across two variables - chronological group and the cognitive stage.
\end{abstract}

Results: Results revealed a significant main effect in the means of the accurate responses for the simile completion tasks across the chronological as well as the cognitive groups.

Conclusion: The ability to understand similes follows a developmental pattern, and probably continues to develop even after 15 years. The responses obtained by the participants in the present study improved with age there by suggesting that the amount and quality of knowledge that a child possesses concerning a figurative expression, does play an important role in the child's comprehension of such higher language aspects.

Keywords: Adolescent; development; figurative; simile

\section{Background}

Learning language is synergistic in nature and the process of its development starts early in human life. Although majority of language development occurs in the infant through preschool years, development continues throughout adolescence. The Centers for Disease Control and
Prevention considers the age range for adolescents as 1019 years and considers 20-24 years olds as young adults. During adolescent development, individuals learn to use more complex language and to communicate differently depending on the situation. The use of figures of speech helps increase the knowledge of vocabulary, organize and memorize new words, and to integrate and improve language 
awareness and use. The language that uses figures of speech is called 'figurative language' serving clearness and beauty in the language. ${ }^{1}$ Studies have revealed that the figurative language is used as frequently as the literal counterparts and in certain instances the usage of the former may be even more frequent than the latter. ${ }^{2-4}$ The frequent occurrence of figurative expressions such as similes in a conversational speech as well as in academic contexts for the middle to upper grade elementary school children have been the area of research concern. A simile inserts an explicit comparator such as 'like' taking the form ' $A$ is like $B$ ' (For e.g., 'The camel is like the ship of the desert'). ${ }^{5}$, and also ' $A$ is as $B$ as $C$ '. (For e.g., 'He is as clever as a fox').

Several studies have been done to examine the ability of typically developing children in the comprehension of the types of figurative language. ${ }^{6-9}$ All these studies indicate that, though there is a basic ability to comprehend figurative expressions during the preschool years ${ }^{10-13}$, refinement of these skills persist atleast throughout their early adulthood ${ }^{14-18}$. Early studies on later language development pertaining to metaphors and similes emphasized on the fact that certain cognitive prerequisites should be present before a child comprehends such expressions. The relationship between cognitive development and figurative language was studied in typically developing adolescents, and the researchers found a steady improvement in the comprehension of figures of speech with a simultaneous development in their cognitive stages (from concrete operational to formal operational thinking). ${ }^{19}$ Studies have found children in their preadolescent years (9-12 years), to exhibit a sudden spurt in competence, ${ }^{20-21}$ with a parallel advancement into the cognitive stage of formal operations. ${ }^{22}$ In spite of India being a multilingual country, studies pertaining to adolescent language are still at its infant stage. As the adolescent language consists of the attainment of higher language skills such as the interpretation and usage of figurative expressions, it would be interesting to know the pattern of their acquisition in a polyglottic setup. Though similes occur more frequently in discourse than metaphors, it is much less investigated than the latter. Studies of this nature are need of the hour ${ }^{23}$, because deficits of comprehension of figurative language ${ }^{24-26}$ largely go undetected in certain children with language disorders. This study aims to determine the developmental trend in the comprehension of similes in typically developing children between $10-15$ years of age.

\section{Methods}

The present study was conducted in a relatively quiet room of an English medium school for typically developing (in terms of language and scholastic development) children in Mangalore, a place located in the Southern part of India. The children were of either L1 (first language) being Kannada/ Tulu (South Indian languages), while L2 (second language) always being English. The ethical clearance was obtained from the Institutional Ethical Committee at Kasturba Medical College, Mangalore and the informed consent was obtained prior to the conduction of the study.

\section{Participants}

The participants in the current study were selected from six age groups $(10-10.11,11-11.11,12-12.11,13-13.11$, 14-14.11 and 15-15.11 years). The six age groups selected for the present study was also classified into the Piaget's cognitive stages. Group 1 and 2 between 10 - 11.11 years was considered to be under the 'concrete-operational stage'; Group 3, 4 and 5 between $12-14.11$ years as the 'late concrete-early formal operational stage', and finally Group 6 between 15 - 15.11 years, as the beginning of the 'formal operational stage'.

The class teachers recruited five children randomly from each group, thereby making a total of 30 participants. They were screened for any significant deficits in speech, language and hearing, or any cognitive issues affecting the academic functioning, using a checklist (Appendix).

\section{Procedure}

A simile being a variant of a metaphor that uses an unambiguous comparator was used in the present study to explore figurative language abilities in children. Studies have concluded that similes were much easier to comprehend than metaphors. Hence the present study targeted using similes than metaphors, because of its explicit nature. ${ }^{27}$ Commonly occurring similes were selected from the child's core curriculum (within the chapters of the English literature, as well as student academic exercises after a chapter). In addition to these, other commonly occurring similes from popular children's literature were also considered for the present study. A total of 38 figurative expressions (similes) were selected for the study. The experimental paradigm followed a sentence (simile) completion task, adapted from another study ${ }^{27}$. The students were given worksheets containing the incomplete expressions and were expected to fill in the missing word. For example: As cool as a (correct responses being 'cucumber', 'iceberg', 'cat', 'swan', 'breeze', etc). As seen from the example, the total number of possible correct responses may be numerous. However, the student was expected to provide atleast one correct response. 


\section{Scoring and Analysis}

A score of one was given for correct responses and incorrect responses received a zero score. The mean of the scores were analyzed under each of the six groups using SPSS (16). Univariate Analysis of Variance was employed to determine the main significant difference across two variables chronological group and the cognitive stage. Bonferroni Post Hoc Analysis was also done to determine the level of significance between each of the six age groups and the cognitive stages.

\section{Results}

Descriptive statistics was employed to determine the mean of the accurate responses for the simile completion tasks across two variables: group-wise and stage-wise. The group-wise is with reference to the calculation of the means under each chronological age group (10-10,11 to $15-15,11$ years). Stage-wise refers to the means calculated under each of Piaget's cognitive stages (concrete-operational, late concrete-early formal operational and formal operational stage). The following tables exhibit the mean values of the accurate responses for the simile completion task across groups and stages respectively.

Table 1: The mean accurate responses for the simile completion task across the age groups (group-wise).

\begin{tabular}{ccc}
\hline Age groups (years) & $\begin{array}{c}\text { Chronological } \\
\text { groups }\end{array}$ & Mean value \\
\hline $10-10 ; 11$ & 1 & 14.8 \\
$11-11 ; 11$ & 2 & 13.4 \\
$12-12 ; 11$ & 3 & 16.8 \\
$13-13 ; 11$ & 4 & 18.8 \\
$14-14 ; 11$ & 5 & 25.6 \\
$15-15 ; 11$ & 6 & 28.4 \\
\hline
\end{tabular}

Table 2: The mean accurate responses for the simile completion task across the Piaget's cognitive stages (stagewise).

\begin{tabular}{ccc}
\hline $\begin{array}{c}\text { Age groups } \\
\text { (years) }\end{array}$ & Piaget's Cognitive stages & $\begin{array}{c}\text { Mean } \\
\text { value }\end{array}$ \\
\hline $10-10 ; 11$ & Concrete-operational stage & 14.1 \\
$11-11 ; 11$ & & \\
$12-12 ; 11$ & Late concrete-early formal & 20.4 \\
$13-13 ; 11$ & operational stage & \\
$14-14 ; 11$ & & \\
$15-15 ; 11$ & Formal operational stage & 28.4 \\
\hline
\end{tabular}

The group-wise comparison reveals a progressive improvement in the mean values across the chronological age groups, with a marked increase at 14 years of age, as revealed in table I. However, an exceptional performance was observed in group 2, which was the only group with decreased scores when compared to the previous age group. According to the stage-wise comparison, the mean accurate responses were observed to increase across the three groups, as shown in table II.

Univariate Analysis of Variance yielded a significant main effect across group-wise and stage-wise, F $(3,24)=4.248$, $\mathrm{p}<0.05$. Multiple comparisons were carried out using Bonferroni Post Hoc test $(\mathrm{p}<0.05)$. The following table (Table III) represents the group-wise comparison across each of the groups.

Table 3: The Bonferroni Post Hoc test values and its level of significance for the accurate responses of the simile completion tasks across all the age groups.

\begin{tabular}{llll}
\hline \multicolumn{2}{c}{ Group-wise comparison } & p-value & Significance \\
\hline Group 1 & Group 2 & 1.000 & NS \\
Group 2 & Group 3 & 1.000 & NS \\
Group 3 & Group 4 & 1.000 & NS \\
Group 4 & Group 5 & 0.235 & NS \\
Group 5 & Group 6 & 1.000 & $\mathrm{NS}$ \\
\hline
\end{tabular}

The above results did not receive any significant difference $(\mathrm{p}>0.05)$ between the groups. Similarly, multiple comparisons were also carried out across the cognitive stages. The following table (Table IV) represents the stagewise comparison.

Table 4: The Bonferroni Post Hoc test values and its level of significance for the accurate responses of the simile completion tasks across Piaget's cognitive stages.

\begin{tabular}{llll}
\hline \multicolumn{1}{c}{ Stage-wise comparison } & p-value & Significance \\
\hline $\begin{array}{l}\text { Concrete } \\
\text { operational } \\
\text { stage }\end{array}$ & $\begin{array}{l}\text { Late concrete- } \\
\text { early formal } \\
\text { operational } \\
\text { stage }\end{array}$ & 0.003 & Sig \\
$\begin{array}{l}\text { Late concrete- } \\
\text { early formal } \\
\text { operational } \\
\text { stage }\end{array}$ & $\begin{array}{l}\text { Formal } \\
\text { operational } \\
\text { stage }\end{array}$ & 0.003 & Sig \\
\hline
\end{tabular}

The above results indicates a significant difference between all the cognitive stages at $\mathrm{p}<0.05$. 


\section{Discussion}

The present study focused on exploring the nature of a figurative expression such as a simile that is explicit in nature. Six age groups $(10-10.11,11-11.11,12-12.11$, 13-13.11, 14-14.11 and 15-15.11 years) were included in the study, with each group consisting of randomly selected five individuals. The six groups were also categorized in terms of the cognitive stages (concrete-operational stage, late concrete-early formal operational stage and the formal operational stage). A simile completion task was administered on the participants. Descriptive statistics and Univariate Analysis of Variance was employed to identify the mean accurate responses and the level of significance between all the groups. Results revealed an increase in the mean accurate responses and a main significant difference across the group-wise and stage-wise variables.

It was observed that participants of group 1 obtained lesser mean accurate responses when compared to group 3; and group 3 obtained a lesser mean value when compared to its subsequent group, and so on. Univariate Analysis of Variance revealed a significant main effect across the chronological age group at $\mathrm{p}<0.05$. This suggests a steady increase in the comprehension of such higher order language skills, being figurative expressions in this study. Hence the current findings can be considered to be in agreement with other studies. ${ }^{14-18}$ which also reveals an improved figurative language abilities with an increase in chronological age. However, Bonferroni Post Hoc test failed to indicate significant differences $(p>0.05)$ in the performance of figurative expressions among the chronological age groups. The fact that majority of the studies done were pertaining to metaphorical expressions as against the similes in the present paper, could be reasoned for this observation.

Furthermore, another aspect of the study was with respect to the allocation of the participants of the study under different cognitive stages of development. In the current study, the groups present under the 'concrete-operational stage' seemed to have performed slightly poorer than 'late concrete-early formal operational' who in turn performed poorer than 'formal operational stage'. This was an expected trend which indicated an increase in the accurate responses across the cognitive stages. Univariate Analysis of Variance revealed a significant main effect across the cognitive stages at $\mathrm{p}<0.05$. To exemplify the results, the Bonferroni Post Hoc test $(\mathrm{p}<0.05)$ also revealed a positive finding. Similar studies were also reported a parallel development across the cognitive stages and figurative language..$^{20-21}$
An interesting finding in the present study was the poorer performance by group 2 compared to group 1 . This pattern did not follow the trend observed with the succeeding groups. However, when the performance of group 2 was analysed from the cognitive perspective, comprising of the concreteoperational stage (group 1 \& 2), a typical developmental sequence was observed. Another possible reason for the deviation could be also due to a small sample size. Moreover, though there was a progressive improvement in the mean accurate responses in the simile completion task, the final group (group 6) had still not attained $100 \%$ accuracy. In line with this, proverb comprehension, which is another aspect of figurative language, was reported to be not mastered in adolescents. ${ }^{28-29}$ This indicates that the development of figurative language is ongoing throughout early adulthood.

Hence, the results of the current study are in accordance with the proposed hypothesis stating that the mean accurate responses for the figurative language production increases with chronological and as well as the cognitive stages. Numerous other studies ${ }^{6-9}$ are also in support of the present finding. The responses obtained by the participants in the present study improved with age there by suggesting that the amount and quality of knowledge that a child possesses concerning a figurative expression, does play an important role in the child's comprehension of such higher language aspects.

\section{Conclusion}

The present research was taken up to study the developmental trend in the understanding of figurative expressions such as similes in the typically developing Indian children between the age groups of $10-15$ years. The results indicated that the ability to understand similes follows a developmental pattern, and probably continues to develop even after 15 years. Moreover it can be concluded that the tasks such as simile completion can be used to assess figurative language in adolescent. However the results of the present study need strengthening by involving larger number of participants and also by including other aspects of figurative language.

\section{Acknowledgment}

We are grateful and thank the school authority for their cooperation to conduct our study and making it a good success. We thank the Dean, Kasturba Medical College, Manipal University, Mangalore, for supporting us to conduct such a study. 


\section{References}

1. Tajalli G. Idioms and Metaphorical Expressions in Translation. Tehran:Samt;2003.

2. Wilson D, Carston R. Metaphor, relevance and the 'emergent property' issue. Mind and Language 2006;21:404-33.

3. Wilson D, Carston R. Metaphor and the 'emergent property' problem: A relevance-theoretic treatment. The Baltic International Yearbook of Cognition, Logic and Communication 2008;3:1-40.

4. Sperber D, Wilson D. A deflationary account of metaphor. In: Gibbs RW, ed. Handbook of Metaphor and Thought. Cambridge: Cambridge University Press; 2008. P 84-108.

5. Verbrugge RR. Transformations in knowing: A realist view of metaphor. In Honeck RP, Hoffman RR, ed. Cognition and Figurative Language. Hillsdale, NJ: Lawrence Erlbaum Associates; 1980. P 87-125.

6. Kogan N, Connor K, Gross A, et al. Understanding visual metaphor: Developmental and individual differences. Monographs of the Society for Research in Child Development 1980;45:27-331.

7. Winner E, Engel M, Gardner H. Misunderstanding metaphor: What's the problem? Journal of Experimental Child Psychology 1980;30:22-32.

8. Cicone M, Gardner H, Winner E. Understanding the psychology in psychological metaphors. Journal of Child Language 1981;8:213-16.

9. Wagner S, Winner E, Cicchetti D, Gardner H. "Metaphorical" mapping in human infants. Child Development 1981;52:728-31.

10. Vosniadou S, Ortony A. The emergence of the literalmetaphorical anomalous distinction in young children. Child Development 1983;54:154-61.

11. Dent $\mathrm{CH}$. The developmental importance of motion information in perceiving and describing metaphoric similarity. Child Development 1984;55:1607-13.

12. Vosniadou S, Ortony A, Reynolds RE, et al. Sources of difficulty in the young child's understanding of metaphorical language. Child Development 1984;55:1588-606.

13. Pearson BZ. The comprehension of metaphor by preschool children. Journal of Child Language 1990; 17:185-203.

14. Boswell DA. Metaphoric processing in the mature years. Human Development 1979;22:373-84.

15. Waggoner JE, Messe MJ, Palermo DS. Grasping the meaning of metaphor: Story recall and comprehension. Child Development 1985;56:1156-66.

16. Kogan N, Chadrow M. Children's comprehension of metaphor in the pictorial and verbal modality. International Journal of Behavioral Development 1986;9:285-95.

17. Siltanen SA. Effects of three levels of context on children's metaphor comprehension. Journal of Genetic Psychology 1989;150:197-215.

18. Kubicka D. Comprehension of standard metaphorical similes by adolescents. Polish Psychological Bulletin 1992;23:47-61.

19. Billow RM. A cognitive developmental study of metaphor comprehension. Developmental Psychology 1975;11:415-23.

20. Lodge DN, Leach EA. Children's acquisition of idioms in the English language. Journal of Speech and Hearing Research 1975;18:521-9.

21. Cometa MS, Eson ME. Logical operations and metaphor interpretation: A Piagetian model. Child Development 1978;49:649-59.

22. Inhelder B, Piaget J. The growth of logical thinking from childhood to adolescence. New York: Basic Books; 1958.

23. Van Der Merwe K. The comprehension of figurative language by Afrikaans-speaking children with and without specific language impairment and by child second language speakers of Afrikaans [Master's thesis]. South Africa: University of Stellenbosch; 2008. Available from http://scholar.sun.ac.za/ handle/10019.1/21912.

24. Bishop DVM, Adams C. Conversational characteristics of children with semantic-pragmatic disorder: II. What features lead to judgment of inappropriacy? British Journal of Disorders of Communication 1989;24:241-63.

25. Nippold MA. Evaluating and enhancing idiom comprehension in language-disordered students. 
Language, Speech, and Hearing Services in Schools 1991;22:100-06.

26. Botting N, Adams C. Semantic and inferencing abilities in children with communication disorders. International Journal of Language Communication Disorders 2005;40:49-66.

27. Hyde-Wright S, Cray B. A teacher's and speech therapist's approach to management. In Mogford-Bevan K, Sadler J, ed. Child Language Disability. 1991;2: P 74-98.
28. Nippold MA, Hegel SL, Ulden LD, et al. Development of proverb comprehension in adolescents: Implications for instruction. Communication Disorders Quarterly 1997;19:49-55.

29. Nippold MA, Uhden LD, Schwarz IE. Proverb explanation through the lifespan: A developmental study of adolescents and adults. Journal of Speech, Language, and Hearing Research 1997;40:245-53. 